\title{
Erratum to: Impact of febrile neutropenia on R-CHOP chemotherapy delivery and hospitalizations among patients with diffuse large B-cell lymphoma
}

\author{
Ruth Pettengell • Hans E. Johnsen • Pieternella J. Lugtenburg • \\ Antonio Salar Silvestre • Ulrich Dührsen • Francesca G. Rossi • \\ Matthias Schwenkglenks • Kate Bendall • Zsolt Szabo • \\ Ulrich Jaeger
}

Published online: 7 December 2012

(C) Springer-Verlag Berlin Heidelberg 2012

\section{Erratum to: Support Care Cancer (2012) 20:647-652 \\ DOI 10.1007/s00520-011-1306-6}

The original version of this article unfortunately contained mistake. The name of the second author "Hans E. Johnsen" was written incorrectly and is now corrected in the author group of this article.

The online version of the original article can be found at http://dx.doi.org/ 10.1007/s00520-011-1306-6.

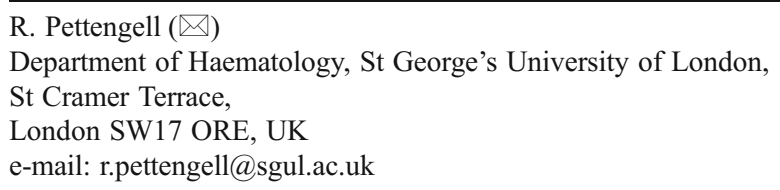

H. E. Johnsen

Department of Hematology, Aalborg Hospital,

Aarthus University Hospital,

Aalborg, Denmark

\section{P. J. Lugtenburg}

Department of Hematology, Erasmus MC,

Rotterdam, Netherlands

\author{
A. S. Silvestre \\ Hematology Department, Hospital del Mar, \\ Barcelona, Spain \\ U. Dührsen \\ Department of Hematology, University Hospital Essen, \\ Essen, Germany
}

F. G. Rossi

UO Ematologia 1-CTMO, Fondazione Policlinico MaRe IRCCS, Milan, Italy

M. Schwenkglenks

Institute of Pharmaceutical Medicine, University of Basel, Basel, Switzerland

\section{K. Bendall}

Biostatistics, Bendall Consultancy Ltd,

London, UK

Z. Szabo

Clinical Development, Amgen (Europe) GmbH,

Zug, Switzerland

U. Jaeger

Department of Internal Medicine I, Division of Hematology and Hemostaseology, Medical University of Vienna,

Vienna, Austria 